\title{
A comprehensive search for microRNAs with expression profiles modulated by oncogenic KRAS: Potential involvement of miR-31 in lung carcinogenesis
}

\author{
KOJI OKUDELA ${ }^{1}$, TAKESHISA SUZUKI ${ }^{1}$, SHIGEAKI UMEDA $^{1}$, YOKO TATEISHI ${ }^{1}$, \\ HIDEAKI MITSUI $^{1}$, YOHEI MIYAGI ${ }^{2}$ and KENICHI OHASHI ${ }^{1}$
}

${ }^{1}$ Department of Pathology, Yokohama City University, Graduate School of Medicine, Kanazawa-Ku, Yokohama 236-0004;
${ }^{2}$ Clinical Research Institute, Kanagawa Prefectural Cancer Center Hospital, Asahi-ku, Yokohama 241-8515, Japan

Received February 17, 2014; Accepted May 13, 2014

DOI: $10.3892 /$ or.2014.3339

\begin{abstract}
Small non-protein coding RNAs that regulate messenger RNA levels, namely microRNAs (miRNAs), have been implicated in the pathogenesis of various diseases. The purpose of the present study was to identify essential miRNAs involved in lung carcinogenesis. Previous studies demonstrated that an investigation into the downstream targets of oncogenic KRAS could be used as a strategy to elucidate the molecular mechanisms involved in lung cancer; therefore, we examined the expression profiles of mRNAs modulated by oncogenic KRAS in the present study. We focused on miR-31 from the miRNAs that were differentially expressed, and evaluated its potential role in the development of lung cancer. miR-31 was upregulated not only by oncogenic KRAS, but also by oncogenic EGFR. The expression of miR-31 was markedly attenuated in some lung cancer cell lines by deleting its host gene locus. The restoration of miR-31 in lung cancer cell lines that lost its expression attenuated their growth activities. The knockdown of miR-31 expression in lung cancer cell lines retaining its expression enhanced anchorage-independent growth activity. These results suggest that miR-31 may be a suppressor that regulates an essential oncogenic pathway, the loss of which may promote lung carcinogenesis.
\end{abstract}

\section{Introduction}

Lung cancer is one of the most common causes of cancer-related mortality in the developed world $(1,2)$. Recurrence has been reported in a large proportion of lung cancer patients in spite of successful resection of the primary tumor $(1,2)$. Although some lung tumors are known to be sensitive to conventional chemotherapeutic agents or certain molecular targeting

Correspondence to: Dr Koji Okudela, Department of Pathology, Yokohama City University, Graduate School of Medicine, 3-9 Fukuura, Kanazawa-ku, Yokohama 236-0004, Japan

E-mail:kojixok@med.yokohama-cu.ac.jp

Key words: miRNA-31, KRAS, lung cancer, carcinogenesis agents, many are not $(3,4)$. Thus, further understanding of the molecular mechanisms involved in lung carcinogenesis is essential for developing novel therapeutic strategies.

Our previous studies, which involved a comprehensive search for the downstream targets of oncogenic KRAS, identified important molecules involved in lung carcinogenesis $(3,5)$. Mutations in driver oncogenes, such as KRAS, EGFR, BRAF, and $A L K$, were found to mutually and exclusively occur, and each of these mutations has been shown to transmit the common essential oncogenic signal that promotes carcinogenesis (6-8). Therefore, the downstream targets of oncogenic $K R A S$ participate not only in $K R A S$-mediated carcinogenesis, but also in other oncogene-mediated carcinogeneses $(3,5)$. Thus, an investigation into the downstream targets of oncogenic KRAS is considered to be an available strategy that can identify common important molecular mechanisms involved in lung cancer.

Small non-protein coding RNAs that regulate messenger RNA levels, namely microRNAs (miRNAs), have been identified and subsequently implicated in the pathogenesis of various diseases. The present study investigated the expression profiles of miRNAs modulated by oncogenic KRAS in airway epithelial cells. We focused on miR-31 from the miRNAs that were differentially expressed, and evaluated its potential role in the development of lung cancer.

\section{Materials and methods}

Cell lines and culture. An immortalized human airway epithelial cell line [16HBE14o, simian virus 40 (SV40)-transformed human bronchial epithelial cells] described by Cozens $e t$ al (9) was kindly provided by D.C. Grunert (California Pacific Medical Center Research Institute). A sub-clone of 16HBE14o cells, described as NHBE-T in this study, was used. Human lung cancer cell lines (A549, H358, H2087, H23, EKVX, H226, H827, H1819, H441, H4006, HOP62, H1299 and H460) and a human embryonic kidney cell line (HEK293T) were purchased from the American Type Culture Collection (ATCC; Manassas, VA, USA). The human lung cancer cell line LC2/ad was purchased from the Riken Cell Bank (Tsukuba, Japan). The human lung cancer cell lines, PC1, PC9 and HARA were 
from Immuno-Biological Laboratories Co. (Gunma, Japan). The human lung cancer cell lines, TKB1, TKB2, TKB4, TKB5, TKB6, TKB7, TKB8, TKB14 and TKB20 were obtained from Dr Hiroshi Kamma via Dr Takuya Yazawa (Kyorin University School of Medicine) (10). Primary small airway epithelial cells (SAEC) were purchased from Sanko Kagaku (Tokyo, Japan).

Plasmid construction. The pro-retrovirus vector bearing KRAS [wild-type (WLD), V12, H61, V12/S35, V12/G37 and V12/C40 mutants] (11) and PIK3CA (WLD, E545K mutant, and H1047R mutant) were previously described (12). Complementary DNA (cDNA) coding EGFR (NM_001964) and BRAF (NM_004333) was PCR-amplified using cDNA from NHBE-T cells as a template and inserted into the pro-retrovirus vector pQCXIP (BD Clontech, Palo Alto, CA, USA). Mutant EGFR (deletion: E745-A750) was PCR-amplified using cDNA from the PC9 lung cancer cell line. EGFR (L858R mutant) and BRAF (V600E mutant) were generated by the method of site-directed mutagenesis. DNA fragments including the miR-31 coding region (MIMAT0000089) flanking approximately a 100 base-pair margin in both directions was PCR-amplified and inserted into the pro-retrovirus vector pLHCX (BD Clontech). Vectors bearing a sense and antisense strand of cDNA were obtained. A pNsi-based miR-31 blocking vector was purchased from Takara Bio Inc. (Kyoto, Japan).

Retroviral-mediated gene transfer. The pro-retrovirus vectors bearing the desired constructs and the pLC10A1 retroviruspackaging vector (Imgenex, San Diego, CA, USA) were cotransfected into HEK293T cells with Lipofectamine 2000 reagent (Invitrogen, Carlsbad, CA, USA). Forty-eight hours after the transfection, conditioned medium was recovered as a viral solution. The desired genes were introduced by incubating cells with the viral solution containing $10 \mu \mathrm{g} / \mathrm{ml}$ of polybren (Sigma, St. Louis, MO, USA). Cells stably expressing the desired genes were selected with $250 \mu \mathrm{g} / \mathrm{ml}$ of hygromycin B or $1,000 \mu \mathrm{g} / \mathrm{ml}$ of neomycin (both from Invitrogen). The pooled clones were used for analyses as follows.

miRNA expression profiling. miRNA expression profiles in empty vector (MOCK)-, KRAS/WLD-, KRAS/V12-, and KRAS/H61-vector transduced NHBE-T cells were comprehensively evaluated with human miRNA microarray (Human miRNA Microarray kit release 16.0, 8x60K, cat. no. G4870A; Agilent Technologies, Santa Clara, CA, USA). Total RNA was extracted from the cells immediately after completing the selection (5 days post-transduction) using the RNA easy kit (Qiagen, Hilden, Germany). Labeling and hybridization was performed according to the manufacturer's recommendations (Agilent Technologies).

Colony formation assays. Cells (appropriate count of $1.0 \times 10^{4}$ to $5.0 \times 10^{4}$ ) were seeded onto a $10 \mathrm{~cm}$ culture dish (Iwaki, Tokyo, Japan), and grown for 10 days. Cells were fixed with methanol and Giemsa-stained, and colonies visible in scanned images were counted.

Growth curve assays. Cells $\left(2.5 \times 10^{5}\right)$ were seeded onto a $10 \mathrm{~cm}$ culture dish, and were grown in DMEM (Sigma) with 10 FBS

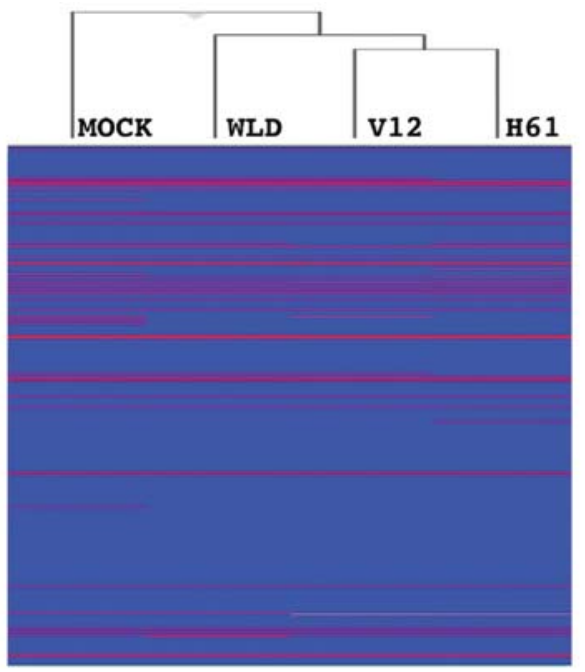

Figure 1. Empty vector (MOCK)-, wild-type KRAS/WLD, oncogenic KRAS/V12, and oncogenic KRAS/H61 were transduced into NHBE-T cells. miRNA expression in the transfectants was comprehensively evaluated with a gene chip microarray. A hierarchical clustering analysis (Ward's method) was performed and a dendrogram was described.

(Sigma) to a semi-confluent state for 5-7 days. Cells were counted, and $2.5 \times 10^{5}$ cells were seeded again onto a $10 \mathrm{~cm}$ dish. Several passages were repeated in the same manner. The sum of population doublings (PDLs) at each point was calculated by the formula SPDL $n=\log _{2}\left(\operatorname{count}_{n} / 2.5 \times 10^{5}\right)+\operatorname{SPDL}_{n-1}$.

Soft agar colony formation assays. Cells $\left(1.25 \times 10^{4}\right)$ were cultured and grown in $1 \mathrm{ml}$ of DMEM-based $0.3 \%$ agar (agar noble; Becton-Dickinson, Sparks, MD, USA) containing $10 \%$ FBS in $3.5 \mathrm{~cm}$ culture dishes (Iwaki) for 4 weeks. The agars were fixed with a buffered $4 \%$ paraformaldehyde solution, and colonies visible in scanned images were counted.

Treatment with an inhibitor for MEK and PI3K. Following infection of the retrovirus vector, cells stably expressing KRAS were selected for 3 days, and were then harvested. Cells were treated with an inhibitor for MEK (PD98059, $50 \mu \mathrm{M}$ ) or PI3K (LY294002, $50 \mu \mathrm{M}$ ) [both from Cell Signaling Technology (CST), Danvers, MA, USA] and their combination for the last $24 \mathrm{~h}$ before the harvest.

Comprehensive search for the downstream target of $m i R-31$. Gene expression in the empty vector (MOCK)-, miR-31 sense strand (SS)-, and miR-31 antisense (AS) strandtransduced NHBE-T cells was comprehensively evaluated with a human gene chip microarray (SurePrint G3 Human Gene Expression 8x60K v2 Microarray kit, cat. no. G4851B; Agilent Technologies). Total RNA was extracted from the cells immediately after completing the selection (5 days post-transduction) using the RNA easy kit (Qiagen). Labeling and hybridization were performed according to the manufacturer's recommendations (Agilent Technologies). Transcripts whose signal values in the miR-31 SS-transduced cells were 5-fold higher or lower than that in both the empty vector-transduced cells and the miR-31 antisense strand-transduced cells were extracted according to the same flow chart as described in a previous study (13). 
Table I. MicroRNAs differentially expressed by the oncogenic KRAS.

\begin{tabular}{|c|c|c|c|c|c|}
\hline Name & Accession & MOCK & KRAS/WLD & KRAS/V12 & KRAS/H61 \\
\hline \multicolumn{6}{|l|}{ Upregulated } \\
\hline hsa-miR-1238 & $\underline{\text { MIMAT0005593 }}$ & 4.53 & 8.45 & 11.49 & 9.58 \\
\hline hsa-miR-31 & MIMAT0000089 & 6.40 & 5.96 & 16.53 & 12.68 \\
\hline hsa-miR-191* & MIMAT0001618 & 5.27 & 9.33 & 11.24 & 9.82 \\
\hline hsa-let-7i & MIMAT0000415 & 109.44 & 98.74 & 224.70 & 164.02 \\
\hline hsa-miR-31* & MIMAT0004504 & 15.01 & 13.44 & 22.80 & 19.14 \\
\hline hsa-miR-29b* & MIMAT0004514 & 2.70 & 2.66 & 7.31 & 3.25 \\
\hline hsa-miR-29b & $\underline{\text { MIMAT0000100 }}$ & 95.87 & 66.36 & 141.79 & 100.44 \\
\hline hsa-miR-625 & $\underline{\text { MIMAT0003294 }}$ & 4.70 & 4.03 & 5.85 & 4.74 \\
\hline hsa-miR-940 & $\underline{\text { MIMAT0004983 }}$ & 12.07 & 11.92 & 15.11 & 12.11 \\
\hline \multicolumn{6}{|l|}{ Downregulated } \\
\hline hsa-miR-30c & $\underline{\text { MIMAT0000244 }}$ & 16.95 & 12.52 & 12.13 & 9.82 \\
\hline hsa-miR-15b & $\underline{\text { MIMAT0000417 }}$ & 208.10 & 154.26 & 148.56 & 102.32 \\
\hline hsa-miR-28-5p & MIMAT0000085 & 5.66 & 4.09 & 3.99 & 3.60 \\
\hline hsa-miR-30a ${ }^{*}$ & $\underline{\text { MIMAT0000088 }}$ & 8.71 & 6.70 & 5.73 & 4.91 \\
\hline hsa-miR-23b & $\underline{\text { MIMAT0000418 }}$ & 8.93 & 6.36 & 5.87 & 4.78 \\
\hline hsa-miR-130a & $\underline{\text { MIMAT0000425 }}$ & 55.99 & 39.19 & 36.31 & 26.76 \\
\hline hsa-miR-210 & MIMAT0000267 & 41.26 & 28.93 & 26.16 & 22.94 \\
\hline hsa-miR-16 & MIMAT0000069 & 157.08 & 110.57 & 96.19 & 73.35 \\
\hline hsa-miR-30e & MIMAT0000692 & 6.70 & 4.47 & 4.03 & 3.68 \\
\hline hsa-miR-196a & MIMAT0000226 & 27.48 & 19.75 & 15.85 & 11.31 \\
\hline hsa-miR-4286 & $\underline{\text { MIMAT0016916 }}$ & 264.56 & 205.35 & 150.73 & 138.68 \\
\hline hsa-miR-15a & MIMAT0000068 & 57.49 & 40.25 & 31.70 & 29.54 \\
\hline hsa-let-7b & MIMAT0000063 & 104.48 & 76.06 & 54.29 & 39.47 \\
\hline hsa-miR-205 & $\underline{\text { MIMAT0000266 }}$ & 116.34 & 74.88 & 59.41 & 50.10 \\
\hline hsa-miR-34a & MIMAT0000255 & 36.32 & 24.83 & 16.71 & 19.56 \\
\hline hsa-miR-1246 & $\underline{\text { MIMAT0005898 }}$ & 52.63 & 36.00 & 23.66 & 21.83 \\
\hline hsa-miR-27b & $\underline{\text { MIMAT0000419 }}$ & 12.85 & 8.09 & 5.49 & 4.76 \\
\hline hsa-miR-429 & $\underline{\text { MIMAT0001536 }}$ & 11.46 & 7.44 & 4.71 & 3.73 \\
\hline
\end{tabular}

Normalized expression levels in transfectants are shown. Accession, gene bank accession no.; WLD, wild-type.

\section{Results}

miRNA expression profiling modulated by oncogenic KRAS. A comprehensive evaluation of the expression of miRNA revealed that oncogenic KRAS-transduced cells had different expression profiles from empty vector- and WLD KRAStransduced cells, as KRAS/V12- and KRAS/H61-transduced cells were classified into a distant branch from the others on a dendrogram described by hierarchical clustering analysis (Fig. 1). The miRNAs that had higher or lower levels in oncogenic KRAS (KRAS/V12 and KRAS/H61)transduced cells than in both mock (MOCK)- and WLD KRAS (KRAS/WLD)-transduced cells are listed in Table I. Quantitative RT-PCR analysis confirmed that the transduction of oncogenic KRAS induced the largest change in let-7i and miR-31 (Fig. 2). Therefore, we focused on these two miRNAs.
Let-7i and miR-31 expression in lung cancer cell lines. Let-7i and miR-31 expression levels were analyzed by quantitative RT-PCR analysis. Let-7i was expressed at various levels in all the cells examined. Let-7i levels were higher in cancer cell lines than in non-cancerous immortalized cell lines and primary airway epithelial cells (Fig. 3). In contrast, miR-31 expression levels were lower in cancer cell lines, and some cell lines $[27.5 \%, 11 / 40$, the loss of miR-31 expression was frequently detected in LCC cell lines $(80.0 \%, 4 / 5)]$ completely lost its expression (Fig. 2). These results prompted us to further investigate the potential significance of the loss of miR-31 expression in lung carcinogenesis.

Effect of the restoration and knockdown of miR-31 on cell growth. The restoration of the miR-31 SS, but not the antisense strand, markedly suppressed the growth of cancer cell lines that lost miR-31 expression, as it decreased the formation of 

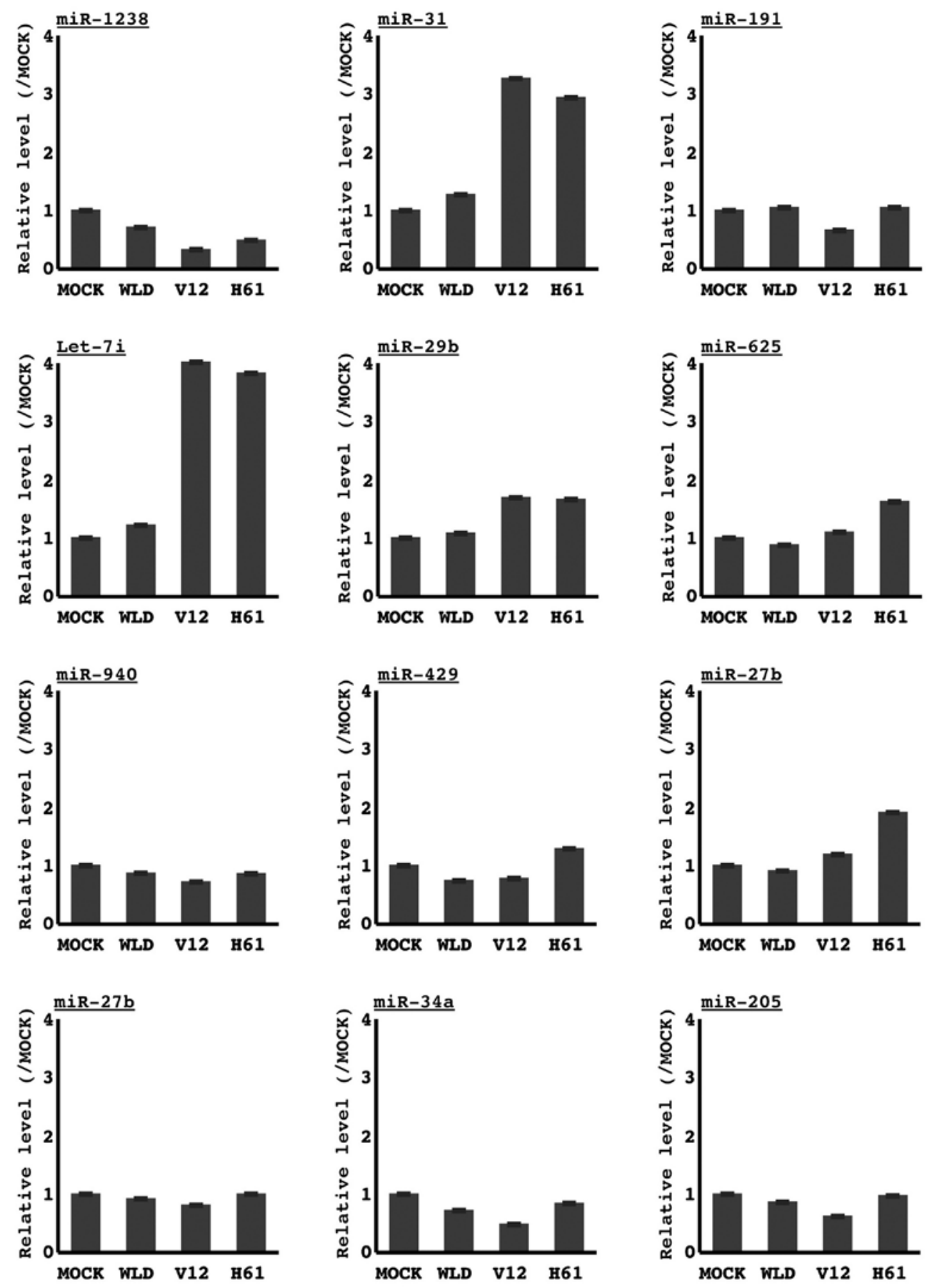

Figure 2. Level of miRNA whose expression is modulated by oncogenic KRAS. The copy number of the targeted miRNA and U6 snRNA was measured by quantitative RT-PCR. The level of miRNA normalized to that of U6 snRNA is presented. MOCK, empty vector-transduced NHBE-T; WLD, wild-type KRAStransduced NHBE-T; V12, oncogenic mutant of KRAS/V12-transduced NHBE-T; H61, oncogenic mutant of KRAS/H61-transduced NHBE-T.

colonies and prolonged the doubling time (Fig. 4, TKB1 and $\mathrm{H} 441$ cells were examined. A representative result in TKB1 cells is shown). On the other hand, the knockdown of miR-31 expression in cell lines that retained its expression resulted in an enhancement in their growth activities in both ordinary media and soft agar (Fig. 5, HARA and A549 cells were examined. A representative result in HARA cells is shown).

Comprehensive search for potential genes modulated by $m i R-31$. A comprehensive evaluation of gene expression profiles revealed that miR-31 SS-transduced cells had a different expression profile from empty vector (mock)- and miR-31 antisense strand (AS)-transduced cells, as miR-31SS-transduced cells were classified into the most distant branch on a dendrogram described from a hierarchical clustering analysis (Fig. 6). Transcripts with expression levels that were $>5$-fold higher in miR-31SS-transduced cells than in mock- and miR-31AS-transduced cells were extracted (Tables II and III).

Involvement of different oncogenic pathways in the induction of $m i R-31$. The expression of miR-31 was also induced by the transduction of oncogenic EGFR [deletion mutation (deletion: 
Table II. Upregulated transcripts.

\begin{tabular}{|c|c|c|c|c|c|c|c|c|c|}
\hline \multirow[b]{2}{*}{ Symbol } & \multirow[b]{2}{*}{ Accession } & \multicolumn{2}{|c|}{ MOCK } & \multicolumn{2}{|c|}{ miR-31SS } & \multicolumn{2}{|c|}{ miR-31AS } & \multirow[b]{2}{*}{ miR-31SS/MOCK } & \multirow[b]{2}{*}{ miR-31SS/AS } \\
\hline & & Signal & Flag & Signal & Flag & Signal & Flag & & \\
\hline NUDT10 & NM_153183 & 0.0119 & A & 1.1978 & $\mathrm{P}$ & 0.0124 & A & 100.8360 & 96.2198 \\
\hline RIPK3 & NM_006871 & 0.0114 & A & 1.0102 & $\mathrm{P}$ & 0.0121 & A & 88.4318 & 83.3022 \\
\hline $\mathrm{C} 2 \mathrm{CD} 4 \mathrm{~B}$ & NM_001007595 & 0.0245 & $\mathrm{~A}$ & 0.5805 & $\mathrm{P}$ & 0.0115 & A & 23.6809 & 50.5356 \\
\hline SERPINI1 & NM_005025 & 0.0112 & A & 0.4145 & $\mathrm{P}$ & 0.0116 & A & 37.0894 & 35.6275 \\
\hline KRTAP10-11 & NM_198692 & 0.0123 & A & 0.4065 & $\mathrm{P}$ & 0.0116 & A & 33.1742 & 35.1714 \\
\hline SLC24A4 & NM_153647 & 0.0357 & A & 1.0444 & $\mathrm{P}$ & 0.0314 & A & 29.2833 & 33.2618 \\
\hline CCDC140 & NM_153038 & 0.0110 & $\mathrm{~A}$ & 0.3725 & $\mathrm{P}$ & 0.0115 & A & 33.9644 & 32.4076 \\
\hline PLA2R1 & NM_007366 & 0.0103 & $\mathrm{~A}$ & 0.2964 & $\mathrm{P}$ & 0.0106 & A & 28.7619 & 27.8916 \\
\hline HTR3D & NM_182537 & 0.0106 & A & 0.3012 & $\mathrm{P}$ & 0.0111 & A & 28.3353 & 27.0245 \\
\hline CXCR2P1 & NR_002712 & 0.0128 & A & 0.2771 & $\mathrm{P}$ & 0.0103 & A & 21.7125 & 27.0160 \\
\hline STEAP2 & NM_001244945 & 0.0099 & A & 0.2577 & $\mathrm{P}$ & 0.0102 & A & 25.9085 & 25.1678 \\
\hline GSG1L & NM_001109763 & 0.0148 & $\mathrm{~A}$ & 0.2657 & $\mathrm{P}$ & 0.0108 & A & 17.9319 & 24.5156 \\
\hline PLAC9 & NM_001012973 & 0.0111 & A & 0.2532 & $\mathrm{P}$ & 0.0109 & A & 22.7315 & 23.2710 \\
\hline MPPED2 & NM_001584 & 0.0119 & A & 0.2784 & $\mathrm{P}$ & 0.0124 & A & 23.4476 & 22.5310 \\
\hline NKX2-8 & NM_014360 & 0.0322 & A & 0.3877 & $\mathrm{P}$ & 0.0179 & A & 12.0409 & 21.6246 \\
\hline ZMAT1 & NM_001011657 & 0.0112 & A & 0.2303 & $\mathrm{P}$ & 0.0116 & A & 20.6436 & 19.8318 \\
\hline CYYR1 & NM_052954.2 & 0.0255 & A & 0.2456 & $\mathrm{P}$ & 0.0128 & A & 9.6355 & 19.2358 \\
\hline MYL1 & NM_079420 & 0.0095 & A & 0.1850 & $\mathrm{P}$ & 0.0098 & A & 19.3932 & 18.7914 \\
\hline ENTPD1 & NM_001776 & 0.0106 & $\mathrm{~A}$ & 0.2072 & $\mathrm{P}$ & 0.0111 & A & 19.5553 & 18.6842 \\
\hline OTOL1 & NM_001080440 & 0.0111 & A & 0.2118 & $\mathrm{P}$ & 0.0115 & A & 19.1511 & 18.4960 \\
\hline BPIFB4 & NM_182519 & 0.0106 & A & 0.2031 & $\mathrm{P}$ & 0.0111 & A & 19.1675 & 18.3275 \\
\hline STARD6 & NM_139171 & 0.0104 & A & 0.1980 & $\mathrm{P}$ & 0.0109 & A & 18.9708 & 18.2463 \\
\hline FAM70A & NM_017938 & 0.0100 & A & 0.1856 & $\mathrm{P}$ & 0.0103 & A & 18.6179 & 18.0836 \\
\hline SLC34A2 & NM_006424 & 0.0117 & A & 0.2084 & $\mathrm{P}$ & 0.0121 & A & 17.8522 & 17.1757 \\
\hline TCL6 & NR_028288 & 0.0119 & A & 0.2186 & $\mathrm{P}$ & 0.0128 & A & 18.3689 & 17.0699 \\
\hline TMEM64 & NM_001008495 & 0.0401 & $\mathrm{~A}$ & 0.4789 & $\mathrm{P}$ & 0.0290 & $\mathrm{~A}$ & 11.9343 & 16.5116 \\
\hline SLC25A21 & NM_030631 & 0.0109 & A & 0.1860 & $\mathrm{P}$ & 0.0113 & $\mathrm{~A}$ & 17.0261 & 16.4283 \\
\hline FABP7 & NM_001446 & 0.0139 & A & 0.1728 & $\mathrm{P}$ & 0.0107 & A & 12.4500 & 16.2039 \\
\hline ADAMTSL2 & NM_014694 & 0.0249 & A & 0.1737 & $\mathrm{P}$ & 0.0110 & $\mathrm{~A}$ & 6.9690 & 15.7766 \\
\hline OR2W5 & NM_001004698 & 0.0112 & A & 0.1846 & $\mathrm{P}$ & 0.0117 & A & 16.4571 & 15.7667 \\
\hline MLANA & NM_005511 & 0.0094 & A & 0.1372 & $\mathrm{P}$ & 0.0098 & A & 14.5261 & 13.9842 \\
\hline LDLRAD2 & NM_001013693 & 0.0119 & A & 0.1733 & $\mathrm{P}$ & 0.0124 & A & 14.6248 & 13.9382 \\
\hline OR5K1 & NM_001004736 & 0.0095 & A & 0.1334 & $\mathrm{P}$ & 0.0098 & A & 14.0985 & 13.5742 \\
\hline TMPRSS4 & NM_019894 & 0.0283 & A & 0.1621 & $\mathrm{P}$ & 0.0122 & A & 5.7287 & 13.2791 \\
\hline GLT25D2 & NM_015101 & 0.0105 & A & 0.1410 & $\mathrm{P}$ & 0.0109 & A & 13.4839 & 12.8923 \\
\hline FMN2 & NM_020066 & 0.0088 & A & 0.1484 & $\mathrm{P}$ & 0.0120 & A & 16.7833 & 12.4044 \\
\hline SLC3A1 & NM_000341 & 0.0154 & A & 0.2346 & $\mathrm{P}$ & 0.0207 & A & 15.2038 & 11.3567 \\
\hline AMICA1 & NM_153206 & 0.0185 & A & 0.2714 & $\mathrm{P}$ & 0.0247 & A & 14.6324 & 10.9989 \\
\hline FAM186B & NM_032130 & 0.0919 & $\mathrm{P}$ & 1.1598 & $\mathrm{P}$ & 0.1056 & $\mathrm{P}$ & 12.6267 & 10.9792 \\
\hline SNORD115-2 & NR_003294 & 0.0116 & A & 0.1296 & $\mathrm{P}$ & 0.0123 & A & 11.1625 & 10.5393 \\
\hline PAX5 & NM_016734 & 0.0110 & A & 0.1198 & $\mathrm{P}$ & 0.0114 & A & 10.9324 & 10.5101 \\
\hline MAGEC2 & NM_016249 & 0.0137 & A & 0.1294 & $\mathrm{P}$ & 0.0125 & A & 9.4181 & 10.3264 \\
\hline IPW & NR_023915 & 0.0221 & A & 0.3631 & $\mathrm{P}$ & 0.0353 & A & 16.3945 & 10.2860 \\
\hline TNFSF11 & NM_033012 & 0.0107 & A & 0.1121 & $\mathrm{P}$ & 0.0111 & A & 10.5095 & 10.0805 \\
\hline SIGLECP3 & NR_002804 & 0.0627 & $\mathrm{P}$ & 0.3595 & $\mathrm{P}$ & 0.0359 & $\mathrm{~A}$ & 5.7295 & 10.0019 \\
\hline WDR49 & AK097556 & 0.0096 & A & 0.0992 & $\mathrm{P}$ & 0.0099 & A & 10.3910 & 9.9812 \\
\hline SATL1 & NM_001012980 & 0.0120 & A & 0.1243 & $\mathrm{P}$ & 0.0127 & A & 10.3606 & 9.7853 \\
\hline
\end{tabular}


Table II. Continued.

\begin{tabular}{|c|c|c|c|c|c|c|c|c|c|}
\hline \multirow[b]{2}{*}{ Symbol } & \multirow[b]{2}{*}{ Accession } & \multicolumn{2}{|c|}{ MOCK } & \multicolumn{2}{|c|}{ miR-31SS } & \multicolumn{2}{|c|}{ miR-31AS } & \multirow[b]{2}{*}{ miR-31SS/MOCK } & \multirow[b]{2}{*}{ miR-31SS/AS } \\
\hline & & Signal & Flag & Signal & Flag & Signal & Flag & & \\
\hline SLC19A3 & NM_025243 & 0.0121 & $\mathrm{~A}$ & 0.1239 & $\mathrm{P}$ & 0.0127 & A & 10.2372 & 9.7655 \\
\hline DPP6 & ВС035912 & 0.0249 & $\mathrm{~A}$ & 0.1543 & $\mathrm{P}$ & 0.0160 & A & 6.2027 & 9.6431 \\
\hline OR5H2 & NM_001005482 & 0.0156 & $\mathrm{~A}$ & 0.1053 & $\mathrm{P}$ & 0.0109 & A & 6.7301 & 9.6315 \\
\hline CIB4 & NM_001029881 & 0.0117 & $\mathrm{~A}$ & 0.1166 & $\mathrm{P}$ & 0.0122 & $\mathrm{~A}$ & 9.9576 & 9.5572 \\
\hline WDFY4 & NM_020945 & 0.0122 & $\mathrm{~A}$ & 0.1211 & $\mathrm{P}$ & 0.0128 & A & 9.9557 & 9.4762 \\
\hline SAMD13 & NM_001010971 & 0.0105 & A & 0.1029 & $\mathrm{P}$ & 0.0109 & A & 9.8322 & 9.4019 \\
\hline NBPF6 & NM_001143988 & 0.0113 & $\mathrm{~A}$ & 0.1090 & $\mathrm{P}$ & 0.0117 & $\mathrm{~A}$ & 9.6855 & 9.2810 \\
\hline FAM135B & NM_015912 & 0.0097 & $\mathrm{~A}$ & 0.0922 & $\mathrm{P}$ & 0.0100 & $\mathrm{~A}$ & 9.4969 & 9.2206 \\
\hline OR4A47 & NM_001005512 & 0.0105 & $\mathrm{~A}$ & 0.1659 & $\mathrm{P}$ & 0.0181 & A & 15.8434 & 9.1669 \\
\hline CCL22 & NM_002990 & 0.0117 & A & 0.1145 & $\mathrm{P}$ & 0.0126 & A & 9.7614 & 9.0799 \\
\hline SLC5A4 & NM_014227 & 0.0105 & A & 0.0987 & $\mathrm{P}$ & 0.0109 & A & 9.4252 & 9.0167 \\
\hline SH3TC1 & NM_018986 & 0.0838 & $\mathrm{P}$ & 0.6744 & $\mathrm{P}$ & 0.0752 & $\mathrm{P}$ & 8.0521 & 8.9695 \\
\hline MYH7 & NM_000257 & 0.0119 & A & 0.1112 & $\mathrm{P}$ & 0.0124 & A & 9.3740 & 8.9612 \\
\hline TXLNG2P & NR_045129 & 0.0111 & $\mathrm{~A}$ & 0.1045 & $\mathrm{P}$ & 0.0117 & A & 9.4000 & 8.9166 \\
\hline NUBPL & NM_025152 & 0.0104 & A & 0.0950 & $\mathrm{P}$ & 0.0109 & A & 9.0971 & 8.7016 \\
\hline CNGA3 & NM_001298 & 0.0094 & A & 0.1537 & $\mathrm{P}$ & 0.0177 & A & 16.2720 & 8.6960 \\
\hline EGR4 & NM_001965 & 0.0105 & A & 0.0938 & $\mathrm{P}$ & 0.0109 & A & 8.9198 & 8.6280 \\
\hline IL24 & NM_001185156 & 1.4258 & $\mathrm{P}$ & 9.1516 & $\mathrm{P}$ & 1.1788 & $\mathrm{P}$ & 6.4187 & 7.7634 \\
\hline RXFP1 & NM_021634 & 0.0111 & A & 0.0888 & $\mathrm{P}$ & 0.0115 & A & 8.0062 & 7.7382 \\
\hline CCDC85C & NM_001144995 & 0.0116 & A & 0.1157 & $\mathrm{P}$ & 0.0154 & A & 9.9729 & 7.4922 \\
\hline TRIM36 & NM_001017397 & 0.0108 & A & 0.1024 & $\mathrm{P}$ & 0.0137 & A & 9.4777 & 7.4839 \\
\hline TACC1 & ВC041391 & 0.0128 & A & 0.1323 & $\mathrm{P}$ & 0.0177 & A & 10.3064 & 7.4633 \\
\hline FAM24B & NM_152644 & 0.0140 & A & 0.0911 & $\mathrm{P}$ & 0.0126 & A & 6.5027 & 7.2256 \\
\hline ITGAL & NM_002209 & 0.0668 & $\mathrm{P}$ & 0.4498 & $\mathrm{P}$ & 0.0641 & $\mathrm{P}$ & 6.7361 & 7.0141 \\
\hline GMCL1P1 & NR_003281 & 0.0104 & A & 0.3532 & $\mathrm{P}$ & 0.0506 & A & 33.9062 & 6.9811 \\
\hline IL24 & NM_001185156 & 10.1283 & $\mathrm{P}$ & 66.0420 & $\mathrm{P}$ & 9.7012 & $\mathrm{P}$ & 6.5205 & 6.8076 \\
\hline PTPN20A & NM_001042387 & 0.0097 & A & 0.0671 & $\mathrm{P}$ & 0.0101 & A & 6.9039 & 6.6542 \\
\hline SRPX & NM_006307 & 0.0090 & $\mathrm{~A}$ & 0.0602 & $\mathrm{P}$ & 0.0093 & A & 6.6622 & 6.4412 \\
\hline RORC & NM_005060 & 0.0096 & A & 0.0797 & $\mathrm{P}$ & 0.0124 & A & 8.3190 & 6.4372 \\
\hline HDAC11 & NM_001136041 & 0.0688 & $\mathrm{P}$ & 0.5473 & $\mathrm{P}$ & 0.0856 & $\mathrm{P}$ & 7.9591 & 6.3925 \\
\hline CRHBP & NM_001882 & 0.0094 & A & 0.0623 & $\mathrm{P}$ & 0.0098 & A & 6.6587 & 6.3675 \\
\hline SPTSSB & NM_001040100 & 0.0111 & A & 0.0738 & $\mathrm{P}$ & 0.0117 & A & 6.6527 & 6.3147 \\
\hline SERPINB11 & NM_080475 & 0.0110 & A & 0.1245 & $\mathrm{P}$ & 0.0201 & $\mathrm{~A}$ & 11.2800 & 6.2069 \\
\hline CC2D2B & XM_003403528 & 0.0102 & A & 0.0656 & $\mathrm{P}$ & 0.0106 & A & 6.4287 & 6.2016 \\
\hline DNAH17 & NM_173628 & 0.0097 & $\mathrm{~A}$ & 0.1610 & $\mathrm{P}$ & 0.0263 & $\mathrm{~A}$ & 16.6227 & 6.1282 \\
\hline DUOXA2 & BX537581 & 0.0087 & A & 0.0552 & $\mathrm{P}$ & 0.0090 & A & 6.3524 & 6.1045 \\
\hline SLC35G3 & NM_152462 & 0.0088 & A & 0.0557 & $\mathrm{P}$ & 0.0092 & A & 6.3135 & 6.0811 \\
\hline SLC17A4 & NM_005495 & 0.0105 & A & 0.0667 & $\mathrm{P}$ & 0.0110 & $\mathrm{~A}$ & 6.3493 & 6.0686 \\
\hline MEOX2 & NM_005924 & 0.0118 & A & 0.0726 & $\mathrm{P}$ & 0.0123 & A & 6.1790 & 5.8922 \\
\hline CLDN8 & NM_199328 & 0.0106 & A & 0.0630 & $\mathrm{P}$ & 0.0109 & $\mathrm{~A}$ & 5.9634 & 5.7753 \\
\hline TMEM108 & NM_023943 & 0.0179 & A & 0.2513 & $\mathrm{P}$ & 0.0440 & A & 13.9997 & 5.7122 \\
\hline DPP6 & NM_001039350 & 0.0124 & A & 0.2982 & $\mathrm{P}$ & 0.0533 & A & 23.9789 & 5.5933 \\
\hline FAM164A & NM_016010 & 0.0103 & A & 0.0598 & $\mathrm{P}$ & 0.0107 & $\mathrm{~A}$ & 5.8098 & 5.5618 \\
\hline GSTTP1 & NR_003081 & 0.0118 & A & 0.0823 & $\mathrm{P}$ & 0.0148 & A & 6.9710 & 5.5445 \\
\hline OR4F6 & NM_001005326 & 0.0118 & $\mathrm{~A}$ & 0.0611 & $\mathrm{P}$ & 0.0113 & $\mathrm{~A}$ & 5.1841 & 5.4305 \\
\hline HEATR7B1 & XM_001721240 & 0.0153 & A & 0.1492 & $\mathrm{P}$ & 0.0277 & A & 9.7300 & 5.3768 \\
\hline DPYS & NM_001385 & 0.0100 & A & 0.0554 & $\mathrm{P}$ & 0.0104 & A & 5.5306 & 5.3504 \\
\hline
\end{tabular}


Table II. Continued.

\begin{tabular}{|c|c|c|c|c|c|c|c|c|c|}
\hline \multirow[b]{2}{*}{ Symbol } & \multirow[b]{2}{*}{ Accession } & \multicolumn{2}{|c|}{ MOCK } & \multicolumn{2}{|c|}{ miR-31SS } & \multicolumn{2}{|c|}{ miR-31AS } & \multirow[b]{2}{*}{ miR-31SS/MOCK } & \multirow[b]{2}{*}{ miR-31SS/AS } \\
\hline & & Signal & Flag & Signal & Flag & Signal & Flag & & \\
\hline OR10Z1 & NM_001004478 & 0.0121 & A & 0.0661 & $\mathrm{P}$ & 0.0127 & A & 5.4614 & 5.2210 \\
\hline PARP10 & NM_032789 & 0.1746 & $\mathrm{P}$ & 1.1198 & $\mathrm{P}$ & 0.2158 & $\mathrm{P}$ & 6.4149 & 5.1885 \\
\hline PIEZO2 & AK092226 & 0.0088 & A & 0.0466 & $\mathrm{P}$ & 0.0091 & A & 5.2934 & 5.0979 \\
\hline ACCN5 & NM_017419 & 0.0090 & A & 0.0478 & $\mathrm{P}$ & 0.0094 & A & 5.2910 & 5.0893 \\
\hline CAPS2 & AF251056 & 0.0105 & A & 0.0636 & $\mathrm{P}$ & 0.0126 & A & 6.0511 & 5.0303 \\
\hline RBPMS & AK057533 & 0.0124 & A & 0.0900 & $\mathrm{P}$ & 0.0180 & A & 7.2453 & 5.0094 \\
\hline
\end{tabular}

MOCK, empty vector-transduced; miR-31SS, miR-31 sense strand-transduced; miR-31 antisense strand-tranduced NHBE-T cells; accession, gene bank accession no.; flag indicates whether gene expression was present (P) or absent (A).
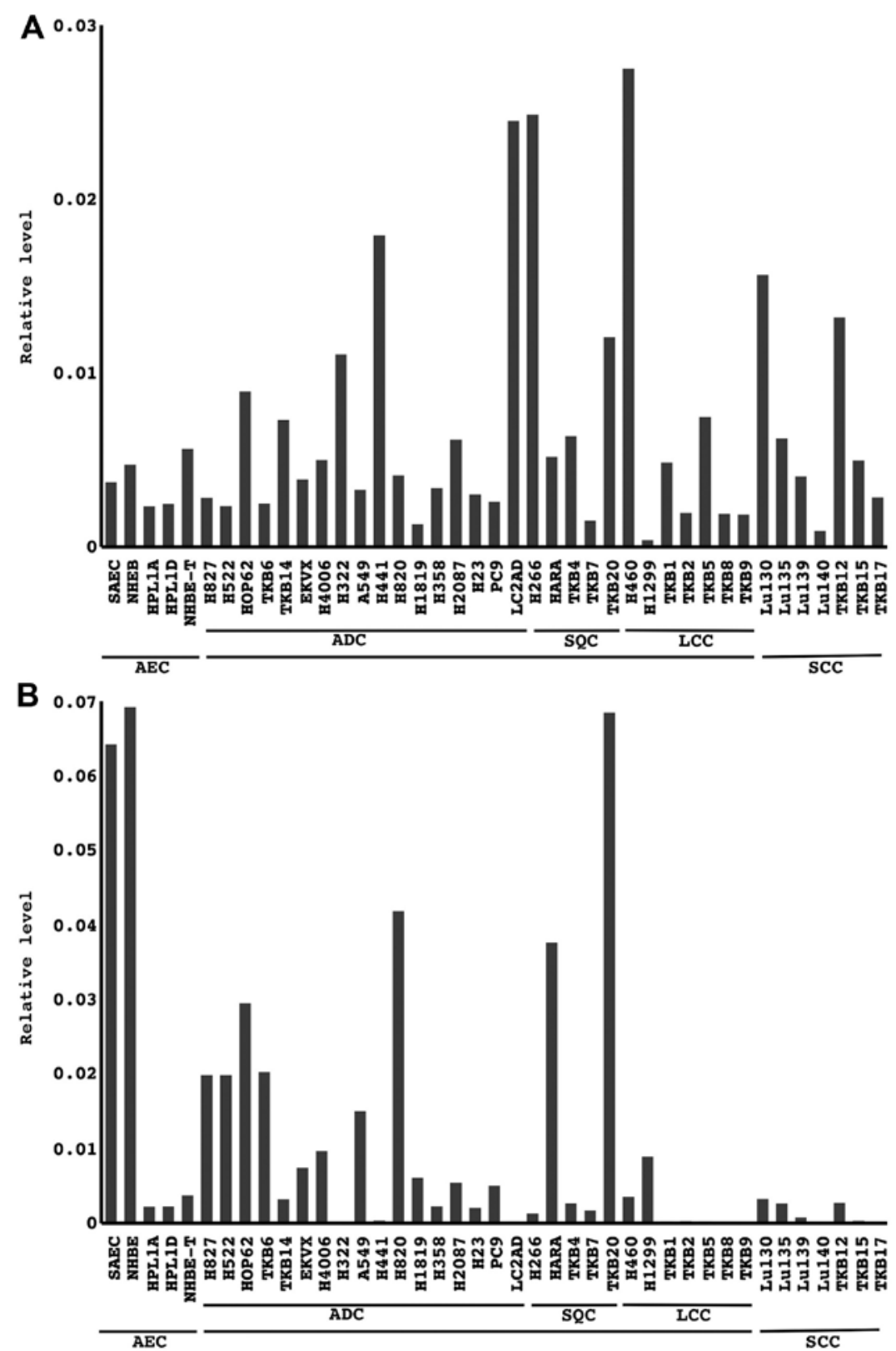

Figure 3. Level of let-7i and miR-31 in non-cancerous and cancer cell lines. The copy number of let-7i, miR-31 and U6 snRNA was measured by quantitative RT-PCR. The level of (A) let-7i or (B) miR-31 normalized to that of U6 snRNA is presented. AEC, airway epithelial cells (non-cancerous cells); ADC, adenocarcinoma cell lines; SQC, squamous cell carcinoma cell lines; LCC, large cell carcinoma cell lines; SCC, small cell carcinoma cell lines. 

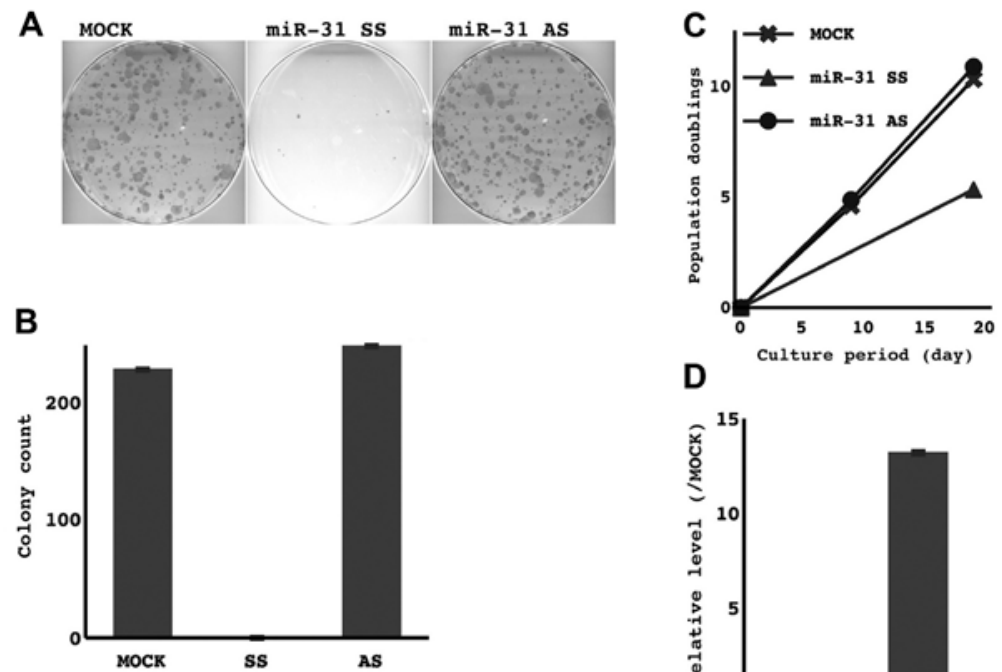

D

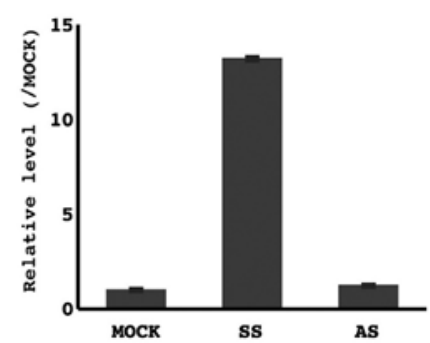

Figure 4. Biological effect of the restoration of miR-31 in lung cancers losing its expression. The representative results from the examination of TKB1 cells are presented. Empty vector (MOCK), the sense strand of miR-31 (SS), and the antisense strand of miR-31 (AS) were transduced. Following a brief selection, the surviving cells were harvested and counted, and $2.0 \times 10^{4}$ were re-seeded onto a $10 \mathrm{~cm}$ dish. (A) After 14 days, the cells were methanol-fixed and Giemsastained. (B) The means and standard deviations (error bars) of colony counts from triplicate experiments are presented. (C) Cells selected were grown and passed several times. Cumulated population doublings are presented. Cells harvested immediately after the selection process were examined for the expression of miR-31 and U6 snRNA by quantitative RT-PCR. (D) The level of miR-31 normalized to that of U6 snRNA is presented.

$\mathrm{A}_{\mathrm{sc1}}$

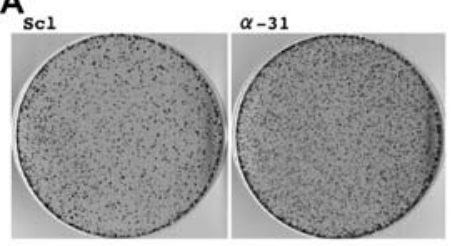

B

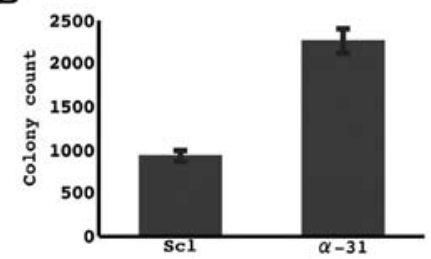

C

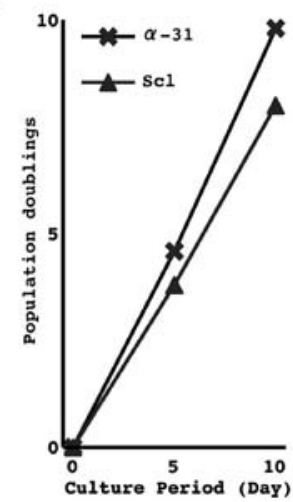

D

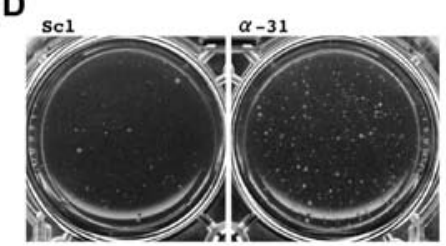

E

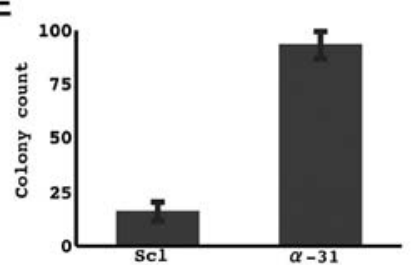

$\mathbf{F}$

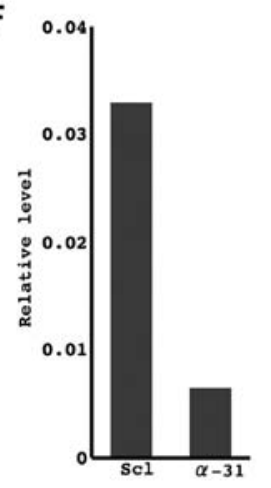

Figure 5. Biological effect of the knockdown of miR-31 in lung cancer cells retaining its expression. The representative results from the examination of HARA cells are presented. The control vector bearing the scrambled random sequence (scl) and the inhibitory vector coding short hairpin RNA targeting for miR-31 $\left(\alpha\right.$-miR-31) were transduced. Following a selection for 10 days, the surviving cells were harvested and counted, and $2.0 \times 10^{4}$ were re-seeded onto a $10 \mathrm{~cm}$ dish (A) After 14 days, the cells were methanol-fixed and Giemsa-stained. (B) The means and standard deviations (error bars) of colony counts from triplicate experiments are presented. The cells after the selection were grown and passed several times. (C) Cumulated population doublings are described. The selected cells $\left(1.25 \times 10^{4}\right)$ were cultured and grown in $1 \mathrm{ml}$ of DMEM-based $0.3 \%$ agar containing $10 \%$ FBS in $3.5 \mathrm{~cm}$ culture dishes for 4 weeks. (D) The agars were fixed with a buffered $4 \%$ paraformaldehyde solution. (E) The means and standard deviations (error bars) of colony counts from triplicate experiments are presented. The cells harvested immediately after the selection process were examined for expression of miR-31 and U6 snRNA by quantitative RT-PCR. (F) The level of miR-31 normalized to that of U6 snRNA is presented. 
Table III. Downregulated transcripts.

\begin{tabular}{|c|c|c|c|c|c|c|c|c|c|}
\hline \multirow[b]{2}{*}{ Symbol } & \multirow[b]{2}{*}{ Accession } & \multicolumn{2}{|c|}{ MOCK } & \multicolumn{2}{|c|}{ miR-31SS } & \multicolumn{2}{|c|}{ miR-31AS } & \multirow[b]{2}{*}{ miR-31SS/MOCK } & \multirow[b]{2}{*}{ miR-31SS/AS } \\
\hline & & Signal & Flag & Signal & Flag & Signal & Flag & & \\
\hline DYTN & NM_001093730 & 58.1445 & $\mathrm{P}$ & 7.8986 & $\mathrm{P}$ & 169.4681 & $\mathrm{P}$ & 0.1358 & 0.0466 \\
\hline MGP & NM_000900 & 0.2369 & $\mathrm{P}$ & 0.0116 & A & 0.2249 & $\mathrm{P}$ & 0.0490 & 0.0516 \\
\hline SAMD9L & NM_152703 & 0.1643 & $\mathrm{P}$ & 0.0149 & A & 0.2193 & $\mathrm{P}$ & 0.0908 & 0.0680 \\
\hline SAA2 & NM_001127380 & 0.3662 & $\mathrm{P}$ & 0.0299 & A & 0.3758 & $\mathrm{P}$ & 0.0817 & 0.0796 \\
\hline SAA4 & NM_006512 & 0.6052 & $\mathrm{P}$ & 0.0521 & $\mathrm{P}$ & 0.6040 & $\mathrm{P}$ & 0.0861 & 0.0863 \\
\hline SAA1 & NM_000331 & 10.6803 & $\mathrm{P}$ & 1.0635 & $\mathrm{P}$ & 10.1069 & $\mathrm{P}$ & 0.0996 & 0.1052 \\
\hline CCR1 & NM_001295 & 0.0807 & $\mathrm{P}$ & 0.0092 & A & 0.0858 & $\mathrm{P}$ & 0.1144 & 0.1077 \\
\hline SAA2 & NM_030754 & 5.8777 & $\mathrm{P}$ & 0.6367 & $\mathrm{P}$ & 5.8671 & $\mathrm{P}$ & 0.1083 & 0.1085 \\
\hline CIITA & NM_000246 & 0.0657 & $\mathrm{P}$ & 0.0104 & A & 0.0925 & $\mathrm{P}$ & 0.1590 & 0.1129 \\
\hline SPTBN1 & NM_003128 & 0.0835 & $\mathrm{P}$ & 0.0101 & A & 0.0893 & $\mathrm{P}$ & 0.1210 & 0.1132 \\
\hline MGP & NM_001190839 & 0.5979 & $\mathrm{P}$ & 0.0643 & $\mathrm{P}$ & 0.5636 & $\mathrm{P}$ & 0.1075 & 0.1141 \\
\hline XAF1 & NM_017523 & 0.6196 & $\mathrm{P}$ & 0.0819 & $\mathrm{P}$ & 0.7122 & $\mathrm{P}$ & 0.1322 & 0.1150 \\
\hline BTBD8 & NM_183242 & 0.0712 & $\mathrm{P}$ & 0.0083 & A & 0.0659 & $\mathrm{P}$ & 0.1162 & 0.1255 \\
\hline PLAC8 & NM_001130715 & 0.0686 & $\mathrm{P}$ & 0.0086 & A & 0.0683 & $\mathrm{P}$ & 0.1259 & 0.1265 \\
\hline OLFM4 & NM_006418 & 0.0751 & $\mathrm{P}$ & 0.0085 & A & 0.0667 & $\mathrm{P}$ & 0.1128 & 0.1269 \\
\hline CLCA2 & NM_006536 & 0.1033 & $\mathrm{P}$ & 0.0105 & A & 0.0787 & $\mathrm{P}$ & 0.1017 & 0.1335 \\
\hline CCL2 & NM_002982 & 0.5769 & $\mathrm{P}$ & 0.0771 & $\mathrm{P}$ & 0.5550 & $\mathrm{P}$ & 0.1337 & 0.1390 \\
\hline SAMD9L & NM_152703 & 0.7186 & $\mathrm{P}$ & 0.1299 & $\mathrm{P}$ & 0.9136 & $\mathrm{P}$ & 0.1807 & 0.1421 \\
\hline TRERF1 & NM_033502 & 0.0967 & $\mathrm{P}$ & 0.0131 & A & 0.0889 & $\mathrm{P}$ & 0.1354 & 0.1472 \\
\hline PLEKHG4 & NM_015432 & 0.0871 & $\mathrm{P}$ & 0.0157 & A & 0.1017 & $\mathrm{P}$ & 0.1797 & 0.1539 \\
\hline ITPK1-AS1 & NR_002808 & 0.0947 & $\mathrm{P}$ & 0.0120 & A & 0.0760 & $\mathrm{P}$ & 0.1262 & 0.1572 \\
\hline DEFB127 & NM_139074 & 0.1531 & $\mathrm{P}$ & 0.0088 & A & 0.0538 & $\mathrm{P}$ & 0.0572 & 0.1627 \\
\hline TFEC & NM_012252 & 0.2166 & $\mathrm{P}$ & 0.0095 & A & 0.0576 & $\mathrm{P}$ & 0.0438 & 0.1648 \\
\hline MEOX1 & NM_004527 & 0.0839 & $\mathrm{P}$ & 0.0131 & A & 0.0792 & $\mathrm{P}$ & 0.1559 & 0.1652 \\
\hline GGT5 & NM_001099781 & 1.6842 & $\mathrm{P}$ & 0.2891 & $\mathrm{P}$ & 1.7144 & $\mathrm{P}$ & 0.1717 & 0.1687 \\
\hline RPGR & NM_001034853 & 0.0956 & $\mathrm{P}$ & 0.0179 & A & 0.1027 & $\mathrm{P}$ & 0.1869 & 0.1741 \\
\hline CD99L2 & ВC025729 & 0.0623 & $\mathrm{P}$ & 0.0109 & A & 0.0623 & $\mathrm{P}$ & 0.1749 & 0.1748 \\
\hline CCNG2 & NM_004354 & 0.0846 & $\mathrm{P}$ & 0.0156 & A & 0.0878 & $\mathrm{P}$ & 0.1848 & 0.1781 \\
\hline TNFSF15 & NM_005118 & 3.6060 & $\mathbf{P}$ & 0.6136 & $\mathbf{P}$ & 3.4121 & $\mathbf{P}$ & 0.1702 & 0.1798 \\
\hline IL7R & NM_002185 & 0.7080 & $\mathrm{P}$ & 0.1181 & $\mathrm{P}$ & 0.6427 & $\mathrm{P}$ & 0.1668 & 0.1837 \\
\hline HSH2D & NM_032855 & 0.4028 & $\mathrm{P}$ & 0.0771 & $\mathrm{P}$ & 0.4128 & $\mathrm{P}$ & 0.1915 & 0.1869 \\
\hline BDKRB1 & NM_000710 & 0.1140 & $\mathrm{P}$ & 0.0108 & A & 0.0578 & $\mathrm{P}$ & 0.0948 & 0.1869 \\
\hline SPARC & NM_003118 & 12.4315 & $\mathrm{P}$ & 2.4446 & $\mathrm{P}$ & 12.9549 & $\mathrm{P}$ & 0.1966 & 0.1887 \\
\hline HSD17B11 & NM_016245 & 0.1320 & $\mathrm{P}$ & 0.0245 & A & 0.1294 & $\mathrm{P}$ & 0.1856 & 0.1894 \\
\hline EBI3 & NM_005755 & 0.0981 & $\mathrm{P}$ & 0.0150 & A & 0.0789 & $\mathrm{P}$ & 0.1531 & 0.1904 \\
\hline ADRA1B & NM_000679 & 1.2211 & $\mathrm{P}$ & 0.2366 & $\mathrm{P}$ & 1.2080 & $\mathrm{P}$ & 0.1938 & 0.1959 \\
\hline
\end{tabular}

MOCK, empty vector-transduced; miR-31SS, miR-31 sense strand-transduced; miR-31 antisense strand-tranduced NHBE-T cells; accession, gene bank accession no.; flag indicates whether gene expression was present (P) or absent (A).

E746-A750), point mutation L858R], but not by oncogenic BRAF (V600E) or oncogenic PIK3CA (E545K, H1047R) (Fig. 7). The expression of miR-31 was consistently not induced by specific mutants in KRAS that activated MEK, RAL-GDS or PI3K (Fig. 7). Inhibitors for MEK (the BRAF-MEK-ERK pathway) or PI3Kinase (the PIK3CA-mediated pathway) interfered with the induction of miR-31 by oncogenic KRAS.

\section{Discussion}

The findings of an initial study on breast cancer suggested that miR-31 could be a tumor suppressor that especially inhibited the invasive and metastatic spread of neoplastic cells (14). Previous studies have supported this initial observation and identified the potential molecular mechanisms responsible 


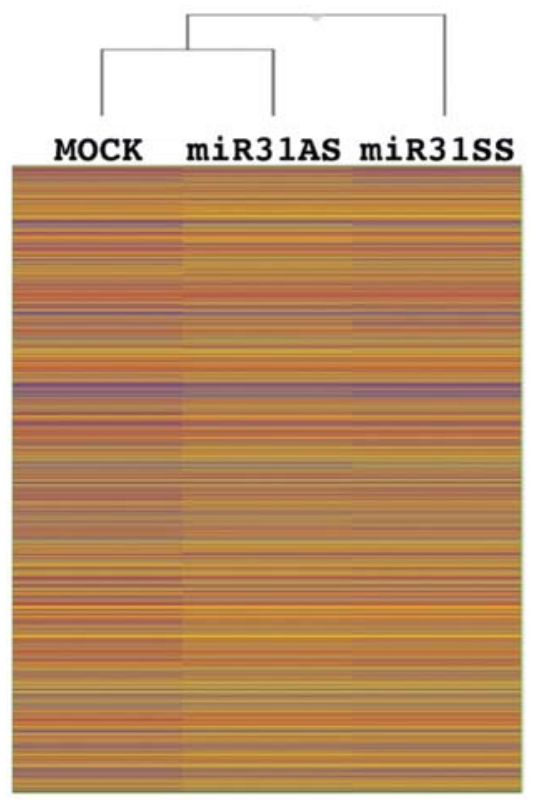

Figure 6. mRNA expression in the empty vector (MOCK)-, the miR-31 sense strand (SS), and the miR-31 antisense strand (AS)-transduced NHBE-T cells was comprehensively evaluated with a gene chip microarray. A hierarchical clustering analysis (Ward's Method) was performed and a dendrogram was described.

for the inhibition of invasion and metastasis by miR-31 (15). miR-31 was also shown to be downregulated in gastric cancer and was suggested to function as a tumor suppressor (16). In contrast, previous studies reported that miR-31 was upregulated in colorectal cancer and may also promote the invasive and metastatic spread of neoplastic cells $(17,18)$. Thus, the potential role of miR-31 in carcinogenesis may differ depending on the type of cancer. The expression of miR-31 in lung cancer has generally been reported to be higher in tumor tissue than in the

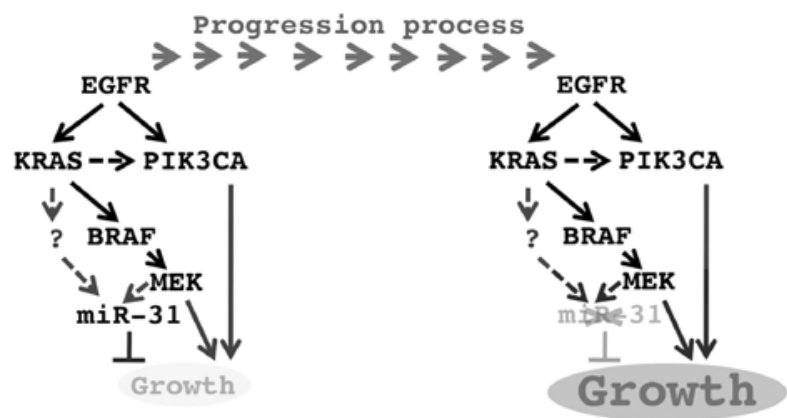

Figure 8 . The putative role of miR-31 in carcinogenesis is described in a scheme. Physiologically, miR-31 may be induced by stimuli promoting cell growth in response to tissue damage and may control regenerative reactions (the left panel). In carcinogenesis, autonomous growth stimuli due to oncogenic mutations may also induce miR-31 that may interfere with unlimited growth. If the machinery to induce miR-31 is disrupted, autonomous stimuli for growth is augmented and further promote the progression of carcinogenesis (the right panel).

corresponding non-tumorous tissue (19-25). However, miR-31 levels have been shown to vary in primary lung tumors. Some tumors expressed miR-31 at lower levels than the corresponding non-tumorous tissue or did not express it at all. miR-31 expression was markedly reduced or completely lost in some lung cancer cell lines (Fig. 3). This result suggested that miR-31 may be a suppressor in lung carcinogenesis. The restoration of miR-31 in lung cancer cell lines that had lost its expression markedly attenuated their growth activities (Fig. 4). The knockdown of miR-31 expression in cell lines that retained its expression enhanced oncogenic phenotypes such as anchorage-independent growth activity (Fig. 5). These results supported miR-31 being a suppressor. However, a recent study demonstrated the oncogenic role of miR-31 in lung carcinogenesis using experiments with different cell lines
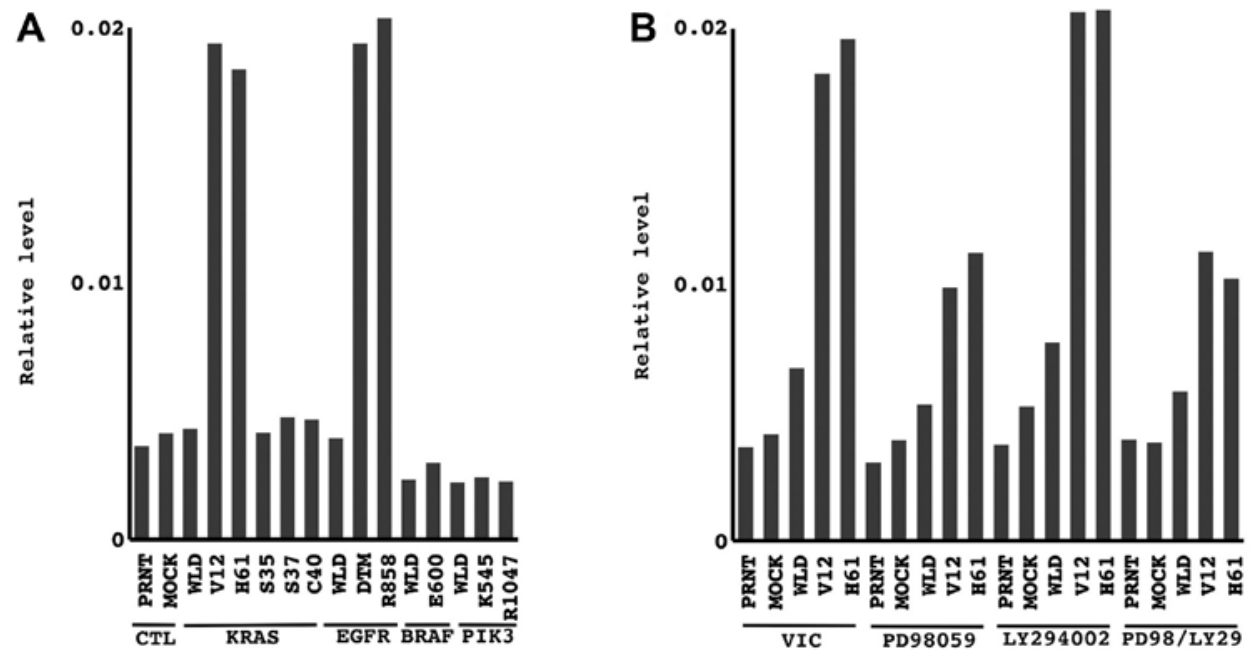

Figure 7. The modulation of miR-31 expression through the essential oncogenic pathway. (A) The level of miR-31 in NHBE-T cells transduced with different mutants of KRAS, EGFR, BRAF and PIK3CA was evaluated. The copy number of miR-31 and U6 snRNA was measured by quantitative RT-PCR. The level of miR-31 normalized to that of U6 snRNA is presented. PRNT, parental NHBE-T; MOCK, empty vector-transduced NHBE-T; WLD, wild-type KRAStransduced NHBE-T; V12, oncogenic mutant of KRAS/V12-transduced NHBE-T; H61, oncogenic mutant of KRAS/H61-transduced NHBE-T; S35, a mutant of KRAS activating only the MEK pathway-transduced NHBE-T; G37, a mutant of KRAS activating only the Ral-GDS pathway-transduced NHBE-T; C40, a mutant of KRAS activating only the PI3K pathway-transduced NHBE-T. (B) The level of miR-31 in NHBE-T cells treated with the inhibitors for MEK (PD98059, $50 \mu \mathrm{M}$ ), PI3K (LY294002, $50 \mu \mathrm{M}$ ), and their combination (PD98/LY29, $50 \mu \mathrm{M}$ each) for $24 \mathrm{~h}$ was evaluated. CTL, control; VIC, vehicle. 
from the ones used in the present study (26). miR-31 may play a pleiotropic role in the development of individual tumors. Further investigations are required to resolve this issue.

In the present study, miR-31 was upregulated not only by oncogenic KRAS, but also by oncogenic EGFR in vitro (Fig. 7). Neither oncogenic BRAF nor oncogenic PIK3CA induced its expression (Fig. 7). Similarly, the specific mutant of KRAS that activated the MEK-mediated pathway only and another specific mutant that activated the PI3K-mediated pathway only did not induce the expression of miR-31 (Fig. 7). On the other hand, the MEK inhibitor, but not PI3K inhibitor, attenuated the oncogenic KRAS-induced expression of miR-31 (Fig. 7). These results suggest that miR-31 could be a common player that regulates the KRAS/EGFR-mediated essential oncogenic pathway (Fig. 8). The MEK-mediated pathway may be necessary, but not sufficient for the induction of miR-31 expression (Fig. 8). The PI3K-mediated pathway may not be involved in its regulation (Fig. 8). A novel pathway may be inducing the expression of miR-31 in cooperation with the MEK-mediated pathway.

This comprehensive search for the potential target of miR-31 revealed that the downregulated transcripts included many molecules mediating the cytokine/chemokine signaling pathway (Tables II and III). TNFSF15, in particular, has been published on an online site as the predicted downstream target for miR-31 (http://mirdb.org/miRDB/index.html). TNFSF15, a member of the tumor necrosis factor (TNF) and TNF receptor superfamilies, regulates cell growth and apoptosis in an autocrine manner, and has been reported to suppress cancer cell growth by inhibiting angiogenesis (27). Thus, TNFSF15 could be a factor that participates in miR-31-induced growth modulations. Future studies that focus on the potential downstream targets of miR-31 may provide insight into the molecular mechanisms involved in lung cancer.

The present study comprehensively searched miRNAs, the expressions of which were regulated by oncogenic KRAS, and focused on miR-31 in order to investigate its potential involvement in lung carcinogenesis. The expression of miR-31 was markedly attenuated in lung cancer cell lines. The restoration of miR-31 in lung cancer cell lines that lost its expression attenuated their growth activities. The knockdown of miR-31 expression in cell lines that retained its expression enhanced oncogenic phenotypes. These results suggest that miR-31 may be a suppressor, the loss of which may promote lung carcinogenesis.

\section{Acknowledgements}

This study was supported by the Japanese Ministry of Education, Culture, Sports and Science (Tokyo Japan), and by a grant from the Yokohama Medical Facility (Yokohama, Japan). We especially thank Emi Honda and Misa Otara (Kanagawa Prefectural Cardiovascular and Respiratory Center Hospital, Yokohama, Japan) for their assistance.

\section{References}

1. Hoffman PC, Cohen EE, Masters GA, et al: Carboplatin plus vinorelbine with concomitant radiation therapy in advanced non-small cell lung cancer: a phase I study. Lung Cancer 38: 65-71, 2002.
2. Spira A and Ettinger DS: Multidisciplinary management of lung cancer. N Engl J Med 350: 379-392, 2004.

3. Okudela K, Woo T and Kitamura H: KRAS gene mutations in lung cancer: particulars established and issues unresolved. Pathol Int 60: 651-660, 2010.

4. Woo T, Okudela K, Yazawa T, et al: Prognostic value of KRAS mutations and $\mathrm{Ki}-67$ expression in stage I lung adenocarcinomas. Lung Cancer 65: 355-362, 2009.

5. Okudela K, Yazawa T, Ishii J, et al: Down-regulation of FXYD3 expression in human lung cancers: its mechanism and potential role in carcinogenesis. Am J Pathol 175: 2646-2656, 2009.

6. Pao W and Girard N: New driver mutations in non-small-cell lung cancer. Lancet Oncol 12: 175-180, 2011.

7. van Eijk R, Licht J, Schrumpf M, et al: Rapid KRAS, EGFR, $B R A F$ and PIK3CA mutation analysis of fine needle aspirates from non-small-cell lung cancer using allele-specific qPCR. PLoS One 6: e17791, 2011.

8. Xu J, He J, Yang H, et al: Somatic mutation analysis of EGFR KRAS, BRAF and PIK3CA in 861 patients with non-small cell lung cancer. Cancer Biomark 10: 63-69, 2011-2012.

9. Cozens AL, Yezzi MJ, Kunzelmann K, et al: CFTR expression and chloride secretion in polarized immortal human bronchial epithelial cells. Am J Respir Cell Mol Biol 10: 38-47, 1994.

10. Yazawa T, Kamma H, Fujiwara M, et al: Lack of class II transactivator causes severe deficiency of HLA-DR expression in small cell lung cancer. J Pathol 187: 191-199, 1999.

11. Okudela K, Yazawa T, Suzuki T, Sugimura H and Kitamura H: Role of 3'-phosphoinositides in oncogenic KRAS-induced modulation of shape and motility of airway epithelial cells. Pathol Int 59: 28-37, 2009.

12. Okudela K, Suzuki M, Kageyama S, et al: PIK3CA mutation and amplification in human lung cancer. Pathol Int 57: 664-671, 2007.

13. Okudela K, Yazawa T, Woo T, et al: Down-regulation of DUSP6 expression in lung cancer: its mechanism and potential role in carcinogenesis. Am J Pathol 175: 867-881, 2009.

14. Valastyan S, Reinhardt F, Benaich N, et al: A pleiotropically acting microRNA, miR-31, inhibits breast cancer metastasis. Cell 137: 1032-1046, 2009.

15. Augoff K, Das M, Bialkowska K, McCue B, Plow EF and SosseyAlaoui K: miR-31 is a broad regulator of $\beta 1$-integrin expression and function in cancer cells. Mol Cancer Res 9: 1500-1508, 2011.

16. Zhang Y, Guo J, Li D, et al: Down-regulation of miR-31 expression in gastric cancer tissues and its clinical significance. Med Oncol 27: 685-689, 2010.

17. Cottonham CL, Kaneko $\mathrm{S}$ and $\mathrm{Xu} \mathrm{L}$ : miR-21 and miR-31 converge on TIAM1 to regulate migration and invasion of colon carcinoma cells. J Biol Chem 285: 35293-35302, 2010.

18. Slaby O, Svoboda M, Fabian P, et al: Altered expression of miR-21, miR-31, miR-143 and miR-145 is related to clinicopathologic features of colorectal cancer. Oncology 72: 397-402, 2007.

19. Guan P, Yin Z, Li X, Wu W and Zhou B: Meta-analysis of human lung cancer microRNA expression profiling studies comparing cancer tissues with normal tissues. J Exp Clin Cancer Res 31: 54, 2012.

20. Jang JS, Jeon HS, Sun Z, et al: Increased miR-708 expression in NSCLC and its association with poor survival in lung adenocarcinoma from never smokers. Clin Cancer Res 18: 3658-3667, 2012.

21. Gao W, Yu Y, Cao H, et al: Deregulated expression of miR-21, miR-143 and miR-181a in non small cell lung cancer is related to clinicopathologic characteristics or patient prognosis. Biomed Pharmacother 64: 399-408, 2010.

22. Võsa U, Vooder T, Kolde R, et al: Identification of miR-374a as a prognostic marker for survival in patients with early-stage nonsmall cell lung cancer. Genes Chromosomes Cancer 50: 812-822, 2011

23. Xing L, Todd NW, Yu L, Fang H and Jiang F: Early detection of squamous cell lung cancer in sputum by a panel of microRNA markers. Mod Pathol 23: 1157-1164, 2010.

24. Yu L, Todd NW, Xing L, et al: Early detection of lung adenocarcinoma in sputum by a panel of microRNA markers. Int $\mathbf{J}$ Cancer 127: 2870-2878, 2010.

25. Tan X, Qin W, Zhang L, et al: A 5-microRNA signature for lung squamous cell carcinoma diagnosis and hsa-miR-31 for prognosis. Clin Cancer Res 17: 6802-6811, 2011.

26. Meng W, Ye Z, Cui R, et al: MicroRNA-31 predicts the presence of lymph node metastases and survival in lung adenocarcinoma patients. Clin Cancer Res 19: 5423-5433, 2013.

27. Duan L, Yang G, Zhang R, Feng L and Xu C: Advancement in the research on vascular endothelial growth inhibitor (VEGI). Target Oncol 7: 87-90, 2012. 